\title{
Reduction of the intake of food and water is responsible for reduction of litter growth when dams are treated with a progesterone antagonist
}

\author{
BY P. VAN DER SCHOOT', T. A. ZEEGERS ${ }^{2}$, F. A. J. MUSKIET ${ }^{2}$, \\ AND E. J. SLAPPENDEL ${ }^{1}$ \\ ${ }^{1}$ Department of Endocrinology and Reproduction, Faculty of Medicine, Erasmus University, \\ Rotterdam. ${ }^{2}$ Central Laboratory for Clinical Chemistry, Academic Hospital, State University, \\ Groningen, The Netherlands
}

(Received I May 1990 - Accepted 23 November 1990)

\begin{abstract}
Treatment of lactating rats with the anti-progestin Mifepristone or Onapristone adversely affects growth of their litters. The present studies aimed to elucidate the underlying mechanism. The treatment did not interfere with the behavioural interactions between mothers and pups, which are required for normal litter growth. Treatment with the antagonists had a stimulatory action on ovarian oestrogen production. However, ovarian hormones did not play a role in litter growth impairment, as this also occurred with lactating ovariectomized rats. Treatment with anti-progestins did not affect the concentrations of the macronutrients in milk (protein, lactose and lipid), nor did it change the fatty acid composition of lipid. Reduced litter growth was not related to a possible direct effect of exposure of the suckling young to the drugs via the milk. Direct injections into them unequivocally affected adrenal gland and testicular development, but did not affect their body-weight development. Milk secretion, as measured by the milk weight accumulating during $\mathbf{6}$ or $\mathbf{2 4} \mathrm{h}$ following sudden removal of litters in advanced lactation, was not impaired by the treatments. However, the ingestion of food and water by dams treated with Mifepristone was significantly below that of control animals. It is concluded that litter growth impairment during treatment of lactating rats with anti-progestin results from the reduction of the intake of food and water by the mother.
\end{abstract}

Anti-progestin: Mifepristone: Onapristone: Litter growth: Lactation: Rat

The anti-progestin Mifepristone affects corpus luteum function in rats. Such action can be demonstrated in both normal and lactating rats. In the latter, suckling provides an almost continuous stimulation of luteal function through its stimulatory effect on pituitary release of prolactin (van der Schoot et al. 1987, 1989, 1990). During our studies, daily treatment of lactating rats with Mifepristone reduced litter growth by about $25 \%$ from day 10 of lactation. This was unlikely to result from reduced suckling time or reduced numbers of milk ejections elicited by sucking pups (van der Schoot et al. 1989).

Mifepristone induces alterations in ovarian activity. These could be responsible for impaired litter growth as ovulations occur despite suckling. Oestrogen secretion associated with imminent ovulation has been postulated to impair lactational performance, as established by impaired litter weight increase (Zeilmaker, 1969). Oestrogens are known to alter production and disposal of plasma lipoproteins, as evidenced by increase of plasma very-low-density lipoproteins (Knopp et al. 1981). Oestrogen administration may directly affect the mammary glands to suppress milk secretion (Bruce \& Ramirez, 1970; Tucker, 1988). Thus, oestrogens may alter qualitative and quantitative aspects of the milk lipid 
fraction. This fraction represents, at least in the human species, the main source of energy (Blanc, 1981) and contains constitutive elements for the newborn (Clandinin et al. 1982; Koletzko et al. 1989). Reduced litter growth when dams are treated with Mifepristone could thus represent the effect of enhanced endogenous oestrogen production resulting from this treatment, and a further analysis could reveal the way by which oestrogens act to show this effect.

However, besides effects of oestrogens on milk production or composition, other factors could underlie the reduced litter growth. The treatment might affect the suckling pups through ingestion of the drug or its metabolites via the milk. Besides anti-progestagenic activity, Mifepristone has been shown to produce anti-glucocorticoid action. The known importance of adrenocorticosteroids for successful lactation (e.g. van der Schoot \& de Greef, 1986) points at another potential mechanism of action of Mifepristone during lactation.

The present experiments were performed in an attempt to elucidate the underlying mechanism of impaired litter growth during treatment of lactating rats with Mifepristone.

\section{MATERIALS AND METHODS \\ Rats}

The experiments were carried out with 2-3-month-old rats obtained from the Wistar breeding colony of TNO-Rijswijk (Rijswijk, The Netherlands). The animals were housed in a regimen of $14 \mathrm{~h}$ light-10 h darkness (lights on 05.00-19.00 hours) and fed ad lib. with a commercial diet and tap water. Females were impregnated by males of proven fertility. Animals were included in the experiments when the litter size was nine or more. On day 2 of lactation (day 1 being the day of parturition) litters were adjusted to ten.

\section{Treatment}

Rats were treated with the progesterone antagonist Mifepristone (RU-38.486; RousselUclaf, France) or Onapristone (ZK-98.299; Schering, Berlin, Germany). Microcrystalline suspensions containing $20 \mathrm{mg}$ in $1 \mathrm{ml}$ olive oil were prepared. Lactating rats received $0.1 \mathrm{ml}$ ( $2 \mathrm{mg}$ antagonist) subcutaneously/d from the day of parturition. Newborn rats received $0.05 \mathrm{ml}$ (1 $\mathrm{mg}$ antagonist) subcutaneously every other day from day 4 (day of birth being day 1).

\section{Experiments}

Anti-progestins, post-partum ovariectomy, and litter-weight changes. The ovarian contribution to impaired litter growth was examined by studying lactating rats which were ovariectomized on the day after parturition. Ovariectomy has no profound effect on lactation beyond the period immediately after surgery (van der Schoot \& de Greef, 1983). Ovariectomy was performed under light diethyl ether anaesthesia on the day after parturition. Daily injections with Mifepristone, Onapristone or olive oil started immediately after surgery. An additional group of rats was treated daily with oestradiol-17 $\beta$-benzoate (OB; $0.01 \mathrm{mg} / \mathrm{d}$ in $0.1 \mathrm{ml}$ olive oil). Litter growth was recorded by weighing every other day. After weighing, each litter was placed with a female of another experimental group in order to get balanced results of weight increases per $2 \mathrm{~d}$ from all litters with all four types of lactating dams.

The possible involvement of Mifepristone ingestion by suckling pups in impaired litter growth. Newborn litters $(n 6)$ were rearranged to ten-pup litters of only females or males. In each litter, half the animals were subcutaneously injected every other day, from day 4 until day 18 of lactation, with $1 \mathrm{mg}$ Mifepristone in $0.05 \mathrm{ml}$ oil, or with oil only. The 
amount of Mifepristone was chosen to ensure that pups obtained more than could ever have been ingested via milk.

The effect of these injections on pup growth was evaluated by weighing the two treatment groups per litter separately every other day. On day 20 , five male and female pups were killed and examined to see whether the treatment with Mifepristone had caused bodily effects such as changes in the weights of adrenal and pituitary glands and testes.

Treatment with Mifepristone, Onapristone, or $O B$ and milk composition. Possible effects of treatment with Mifepristone or Onapristone on milk composition were examined in rats with ovaries in situ, whereas the possible effects of treatment with $O B$ were examined in rats ovariectomized on the day after parturition. After $21 \mathrm{~d}$ of successful lactation, litters were removed from their mothers. After $24 \mathrm{~h}$, milk was expressed through the nipples from the engorged mammary glands: $1-2.5 \mathrm{ml}$ was easily obtained from the rats treated with Mifepristone or Onapristone which allowed for analysis of samples from individual rats. However, expression of milk from rats which had been treated with OB occurred only with great difficulty and individual animals gave no more than $0.2-0.8 \mathrm{ml}$ from their twelve nipples. Milk expressed from two to three rats was pooled to give samples of $1.5 \mathrm{ml}$ or more, the amount required for proper milk composition analysis. Samples were stored at $-20^{\circ}$ for later analysis. Analysis comprised determination of the concentrations $(\mathrm{g} / \mathrm{l})$ of protein (Lowry et al., 1951), lactose (Jensen et al. 1986), and fatty acids (van der Steege et al. 1987). Triacylglycerol concentration was calculated as one-third of the sum of the concentrations of individual fatty acids, taking molecular weights into account. Results of fatty acid analysis are presented as mean values in treatment groups.

Mifepristone, milk secretion, and intake of food and water. The effect of treatment with Mifepristone or OB on milk secretion in advanced lactation was estimated in two ways. First, an estimate of secreted amount of milk weight was made by measuring the weight of the left inguinal mammary gland pad at weaning on day 22 of lactation or $24 \mathrm{~h}$ after weaning. Second, milk secretion was estimated on day 18 of lactation in two further groups of four rats each. Litters were removed from their mothers on day 18 at zero time and the weights of the dams and litters were recorded. After $6 \mathrm{~h}$ these weights were recorded again and the litters were reunited with their own mothers. Weighing was repeated 1 and $2 \mathrm{~h}$ after reunion.

Consumption of food and water by lactating dams was estimated by daily weighing of the available amounts of pelleted food and the water bottles between days 10 and 17 of lactation. This rather crude approach seemed appropriate, provided that care was taken to use bottles which did not lose water via ways other than drinking, and that only large food pellets were provided. Additionally, weights of dams and litters were recorded daily to allow for the calculation of 'food efficiency', i.e. the ratio between daily intake (food + water; $g$ ) and the daily increase ( $\mathrm{g}$ ) of the weight of litter + dam.

\section{Statistics}

Results were analysed with Student's $t$ test, or parametric one- or two-way analysis of variance followed by Tukey's honestly significant difference test (Kirk, 1968). $P=0.05$ was adopted as the upper limit for statistical significance of observed differences.

\section{RESULTS}

Anti-progestins, post-partum ovariectomy, and litter weight changes

The results are presented in Tables 1 and 2. Treatment of lactating ovariectomized rats with Mifepristone or Onapristone reduced litter weight gain. Between days 2 and 22 of lactation, the weight increment of ten-pup litters with unoperated or control ovariectomized dams 
Table 1. Growth of ten-pup litters with intact and ovariectomized ${ }^{*}$ rats treated with Mifepristone or Onapristone $(2 \mathrm{mg} / \mathrm{d})$, oestradiol-17 $\beta$-benzoate $(0.01 \mathrm{mg} / \mathrm{d})$ or oil solvent $(0 \cdot 1 \mathrm{ml}) \dagger$

(Mean values with their standard errors for six litters)

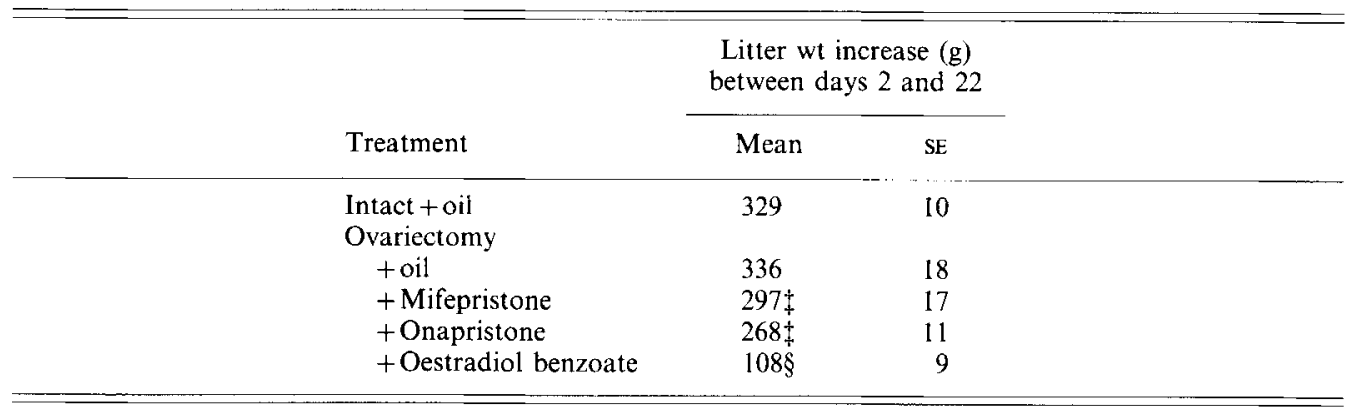

* Ovariectomy on day after parturition.

$\dagger$ For details of treatments, see p. 18.

$\ddagger$ One-way ANOVA: weight increase was significantly less than that for intact + oil and ovariectomy + oil groups.

$\$$ One-way ANOVA: weight increase was significantly less than that of all other groups.

Table 2. Effect of treatment with Mifepristone, Onapristone, oestradiol-17 $\beta$-benzoate $(O B)$ or oil solvent on body and organ weights of intact and ovariectomized (OVX) lactating rats at the end of lactation*

(Mean values with their standard errors for six rats per group unless otherwise indicated)

\begin{tabular}{|c|c|c|c|c|c|c|c|c|c|c|}
\hline \multirow[b]{3}{*}{ Treatment } & \multirow{2}{*}{\multicolumn{2}{|c|}{ Body-wt (g) }} & \multirow{2}{*}{\multicolumn{2}{|c|}{$\begin{array}{c}\text { Adrenal } \\
\text { gland (mg) }\end{array}$}} & \multirow{2}{*}{\multicolumn{2}{|c|}{ Uterus (mg) }} & \multicolumn{4}{|c|}{ Inguinal mammary gland $(\mathrm{mg}) \dagger$} \\
\hline & & & & & & & \multicolumn{2}{|c|}{ At weaning } & \multicolumn{2}{|c|}{$24 \mathrm{~h}$ later } \\
\hline & Mean & $\mathrm{SE}$ & Mean & $\mathrm{SE}$ & Mean & $\mathrm{SE}$ & Mean & $\mathrm{SE}$ & Mean & $\mathrm{SE}$ \\
\hline $\begin{array}{l}\text { Intact + oil solvent } \\
\text { OVX }\end{array}$ & 268 & 8 & 43 & 2 & 400 & 41 & 6053 & 656 & 11216 & 887 \\
\hline + Oil solvent & 277 & 8 & 46 & 1 & 106 & 2 & 6532 & 544 & 15260 & 1998 \\
\hline + Mifepristone & 280 & 2 & 46 & 3 & 119 & 6 & 7065 & 641 & 12479 & 1082 \\
\hline +Onapristone & 272 & 10 & 43 & 2 & 108 & 4 & 5631 & 718 & 11631 & 663 \\
\hline \multirow[t]{2}{*}{$+\mathrm{OB}$} & 244 & 6 & 46 & 3 & 739 & 43 & 5019 & 227 & 10429 & 345 \\
\hline & \multicolumn{2}{|c|}{ 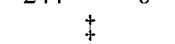 } & \multicolumn{2}{|c|}{ NS } & \multicolumn{2}{|c|}{$\S$} & \multicolumn{2}{|c|}{$\|$} & \multicolumn{2}{|c|}{$\|$} \\
\hline
\end{tabular}

NS, not significant.

* For details of treatments, see p. 18 .

$\dagger$ Mean values for three rats per treatment group.

$\ddagger$ One-way ANOVA: OB-treated group was different from all other groups.

$\$$ One-way ANOVA : OVX groups were different from intact group; OVX + OB group was different from three other OVX groups.

$\|$ Two-way ANOVA: no difference between groups $\left(F_{4,10} 2.5 ; P>0.05\right)$ but difference between 0 and $24 \mathrm{~h}$ $\left(F_{1,10} 38 ; P<0 \cdot 001\right)$.

was significantly higher than those of litters with dams treated with either anti-progestin. Impairment of litter weight gain was in the same order for both compounds. Impairment was much less than that with dams treated with $O B$. The treatment with the anti-progestins did not affect the body-weights of the ovariectomized dams. The post-ovariectomy decrease in weight of the uterus was not altered under the influence of the compounds. OB treatment 
resulted in lower body-weight and increased uterine weight at the end of lactation. The dams' adrenal gland weights, or the weights of the inguinal mammary gland pads at the end of lactation or $24 \mathrm{~h}$ after weaning were similar in all five groups (Table 2).

\section{The possible involvement of Mifepristone ingestion by suckling pups in impaired litter growth}

Injections of Mifepristone into newborn male and female pups did not affect pup growth: between days 10 and 20 of lactation, male and female pups grew equally well, regardless of whether they were injected regularly with oil (increase 108 (SE 3) g/five pups per $10 \mathrm{~d}$; sexes combined) or with Mifepristone in oil (103 (SE 3) g/five pups per 10 days; paired $t$ test: $P=0 \cdot 16$ ).

At autopsy on day 20,2 d after the last injections of either Mifepristone or oil, there were no obvious external bodily signs of the exposure of male or female pups to Mifepristone. However, the weights of adrenal glands (both sexes) and testes were significantly affected (Table 3).

\section{Treatment with Mifepristone, Onapristone, or $O B$ and milk composition}

The results of the analysis of macronutrients and fatty acid composition of milk are presented in Tables 4 and 5 respectively. Neither of the anti-progestins affected macronutrient or fatty acid composition. OB did not change macronutrients, but did change fatty acid composition. Most remarkable were the changes in the relative amounts of mono-unsaturated fatty acids (notably $14: 1 n-5,16: 1 n-7$, and $18: 1 n-7$ ), polyunsaturated fatty acids (PUFA; notably long chain PUFA and 18:2n-6) and mediumchain saturated fatty acids (notably 6:0, 12:0, and 14:0).

Autopsy of the females immediately after milking (Table 6) did not reveal effects of antiprogestin on their body-weight, mammary gland weight, adrenal gland weight or uterine weight. In accordance with earlier observations, ovarian weight in Mifepristone-treated rats had increased due to one or more ovulations from about day 13 of lactation.

\section{Mifepristone, milk secretion and intake of food and water}

The results of the first estimate of milk secretion are presented in Tables 2 and 6 . The left mammary gland pads in intact rats, $24 \mathrm{~h}$ after litter removal, were of equal weight in all treatment groups (Table 6). In the experiment with ovariectomized rats, mammary gland pad weights were not significantly different between the five groups at either zero time or after $24 \mathrm{~h}$, but the difference between 0 and $24 \mathrm{~h}$ was highly significant throughout (Table 2). Some reservation might arise in view of the low number of observations. However, the results in Table 2 add to those in Table 6 and offer a similar result in this respect.

On the assumption that the left inguinal gland pad represents one-quarter of the total amount of glandular tissue it is estimated that in the order of $4 \times 6=24 \mathrm{~g}$ milk had accumulated over the last $24 \mathrm{~h}$ in all groups.

Results of litter weight gain and dams' intake of food and water between days 10 and 17 of lactation are presented in Table 7. Treatment with Mifepristone significantly decreased litter weight gain and intake of both food and water through this period of lactation. There was a highly significant correlation between litter growth and the daily intake of food and water by the respective mothers (correlation coefficient $0.86 ; P=0.001$ ). The intake of food and water:litter weight increase ratio appeared identical in the two groups. Daily intake of food and water were also highly correlated (correlation coefficient $0.89 ; P=0.0001$ ).

Results of the estimation of milk secretion following the second protocol are presented in Table 8. Separation of mothers and their litters for $6 \mathrm{~h}$ on day 17 resulted in appreciable accumulation of milk. During the first hour after reunion, litters in both groups showed 
Table 3. Effect of injections of Mifepristone in infancy $(1 \mathrm{mg}$ in $0.05 \mathrm{ml}$ oil per $2 \mathrm{~d}$ from day 4), or oil only, on body and organ weights in developing male and female rats $\dagger$ (Mean values with their standard errors for five rats per group; autopsy on day 20 after last injection on day 18)

\begin{tabular}{|c|c|c|c|c|c|c|c|c|c|c|}
\hline \multirow[b]{2}{*}{ Treatment } & \multicolumn{2}{|c|}{ Body-wt (g) } & \multicolumn{2}{|c|}{ Testis (mg) } & \multicolumn{2}{|c|}{ Uterus (mg) } & \multicolumn{2}{|c|}{ Adrenal (mg) } & \multicolumn{2}{|c|}{$\begin{array}{c}\text { Hypophysis } \\
\text { (mg) }\end{array}$} \\
\hline & Mean & SE & Mean & $\mathrm{SE}$ & Mean & $\mathrm{SE}$ & Mean & $\mathrm{SE}$ & Mean & $\mathrm{SE}$ \\
\hline \multicolumn{11}{|l|}{ Females } \\
\hline Oil & $37 \cdot 6$ & 0.6 & & & 24 & 1 & $5 \cdot 6$ & $0-4$ & $2 \cdot 6$ & $0 \cdot 2$ \\
\hline Mifepristone & $38 \cdot 2$ & $0 \cdot 5$ & & & 22 & 1 & $4.0^{*}$ & $0-3$ & $2 \cdot 3$ & $0 \cdot 3$ \\
\hline \multicolumn{11}{|l|}{ Males } \\
\hline Oil & $39 \cdot 4$ & $1 \cdot 0$ & 75 & 4 & & & $6 \cdot 1$ & $0 \cdot 2$ & $2 \cdot 3$ & $0 \cdot 1$ \\
\hline Mifepristone & $39 \cdot 6$ & 0.7 & $45^{*}$ & 2 & & & $3 \cdot 8^{*}$ & 0.3 & $2 \cdot 1$ & $0 \cdot 1$ \\
\hline
\end{tabular}

Mean values were significantly different from corresponding oil group (Student's $t$-test: ${ }^{*} P<0.01$ ).

$\dagger$ For details of treatments, see p. 18.

Table 4. Effect of the daily treatment of lactating rats with progesterone antagonists or oestradiol-17 $\beta$-benzoate $(O B)$ on macronutrient composition of their milk*

(Mean values with their standard errors)

\begin{tabular}{|c|c|c|c|c|c|c|}
\hline \multirow[b]{2}{*}{ Treatment } & \multicolumn{2}{|c|}{ Protein $(\mathrm{g} / \mathrm{l})$} & \multicolumn{2}{|c|}{ Lactose $(\mathrm{g} / 1)$} & \multicolumn{2}{|c|}{$\begin{array}{c}\text { Total } \\
\text { triacylglycerols } \dagger(\mathrm{g} / 1)\end{array}$} \\
\hline & Mean & $\mathrm{SE}$ & Mean & SE & Mean & $\mathrm{SE}$ \\
\hline Oil & 97 & 5 & 24 & 2 & 63 & 3 \\
\hline Mifepristone & 104 & 4 & 22 & 1 & 67 & 5 \\
\hline Onapristone & 94 & 5 & 18 & 2 & 76 & 5 \\
\hline OB & 99 & 6 & 19 & 2 & 84 & 6 \\
\hline \multicolumn{7}{|l|}{ ANOVA } \\
\hline$F(\mathrm{df} 3)$ & \multicolumn{2}{|c|}{0.8} & \multicolumn{2}{|c|}{$2 \cdot 0$} & \multicolumn{2}{|c|}{$2 \cdot 2$} \\
\hline$P$ & \multicolumn{2}{|c|}{0.49} & \multicolumn{2}{|c|}{0.14} & \multicolumn{2}{|c|}{0.12} \\
\hline
\end{tabular}

* For details of treatments, see pp. 18-19.

$\uparrow$ Details of fatty acid composition are presented in Table 5.

considerable weight increase, and mothers showed a weight decrease accordingly. During the second hour of reunion, neither the litters nor their mothers showed a further weight change. Results in the two groups were not statistically significantly different.

\section{DISCUSSION}

The present experiments confirm the earlier observations that treatment of lactating rats with Mifepristone interferes with normal litter weight development during the second half of the lactation period. Reduced litter weight increase does not seem to result from reduced time that dams spend with them or with the ease by which suckling evokes milk ejections (Lincoln et al. 1973; van der Schoot et al. 1989). The experiments of the present study were designed to elucidate the underlying mechanism.

Decreased litter growth was observed during treatment with both Mifepristone and Onapristone, two potent anti-gestagenic compounds (Neef et al. 1984; Philibert, 1984). The 
Table 5. Fatty acid composition (mol/100 mol total fatty acids) of rat milk after treatment of lactating rats for 3 weeks with Mifepristone, Onapristone, oestradiol-17 $\beta$ benzoate $(O B)$ or oil $\dagger$

\begin{tabular}{|c|c|c|c|c|c|}
\hline Treatment & Untreated & Oil & Mifepristone & Onapristone & $\mathrm{OB}$ \\
\hline \multicolumn{6}{|l|}{ Fatty acid } \\
\hline $6: 0$ & 0.48 & 0.49 & $0 \cdot 43$ & 0.47 & 0.36 \\
\hline $8: 0$ & $12 \cdot 0$ & $14 \cdot 7$ & $12 \cdot 3$ & 13.8 & $12 \cdot 3$ \\
\hline $10: 0$ & $24 \cdot 6$ & $26 \cdot 8$ & $25 \cdot 1$ & $24 \cdot 9$ & $23 \cdot 3$ \\
\hline $12: 0$ & 12.6 & $11 \cdot 2$ & $11 \cdot 6$ & $10 \cdot 2$ & 8.9 \\
\hline $14: \ln -5$ & 0.04 & 0.04 & $0 \cdot 04$ & 0.04 & $0.06^{*}$ \\
\hline $14: 0$ & $7 \cdot 2$ & $4 \cdot 8$ & $5 \cdot 8$ & $4 \cdot 7$ & $4 \cdot 0$ \\
\hline $16: 1 n-7$ & $0 \cdot 9$ & $1 \cdot 0$ & $1 \cdot 1$ & 10 & $1 \cdot 5^{*}$ \\
\hline $16: 0$ & $12 \cdot 0$ & $10 \cdot 1$ & $11 \cdot 6$ & $11 \cdot 7$ & 12.4 \\
\hline $18: 3 n-6$ & $0 \cdot 1$ & 0.04 & $0 \cdot 1$ & $0 \cdot 06$ & 0.06 \\
\hline $18: 2 n-6$ & 110 & $11 \cdot 8$ & $13 \cdot 0$ & $13 \cdot 0$ & $15 \cdot 8^{*}$ \\
\hline $18: \ln -9$ & $13 \cdot 5$ & $13 \cdot 6$ & $13 \cdot 4$ & $14 \cdot 3$ & 14.6 \\
\hline $18: \ln -7$ & 10 & $1 \cdot 1$ & $1 \cdot 2$ & $1 \cdot 2$ & $1 \cdot 1$ \\
\hline $18: 0$ & 2.9 & 2.9 & $3 \cdot 0$ & $3 \cdot 1$ & $3 \cdot 3$ \\
\hline $20: 4 n-6$ & $0 \cdot 4$ & 0.4 & $0 \cdot 4$ & $0 \cdot 4$ & $0 \cdot 5$ \\
\hline $20: 5 n-3$ & $0 \cdot 2$ & $0 \cdot 1$ & $0 \cdot 1$ & $0 \cdot 1$ & $0 \cdot 2$ \\
\hline $20: 3 n-9$ & $0 \cdot 04$ & 0.05 & 0.05 & 0.05 & 0.06 \\
\hline $20: 3 n-6$ & 0.1 & $0 \cdot 1$ & $0 \cdot 1$ & $0 \cdot 1$ & $0 \cdot 1$ \\
\hline $20: 2 n-6$ & $0 \cdot 2$ & $0 \cdot 2$ & $0 \cdot 2$ & 0.2 & $0 \cdot 2$ \\
\hline $20: \ln -9$ & $0 \cdot 2$ & $0 \cdot 2$ & $0 \cdot 2$ & 0.2 & $0 \cdot 2$ \\
\hline $20: 0$ & 0.06 & 0.06 & $0-06$ & 0.05 & 0.06 \\
\hline $22: 6 n-3$ & $0 \cdot 1$ & $0 \cdot 1$ & $0 \cdot 1$ & $0 \cdot 1$ & $0 \cdot 2$ \\
\hline $22: 4 n-6$ & 0.1 & $0 \cdot 1$ & $0 \cdot 1$ & $0 \cdot 1$ & $0 \cdot 1$ \\
\hline $22: 5 n-3$ & $0 \cdot 1$ & $0 \cdot 2$ & $0 \cdot 1$ & $0 \cdot 1$ & $0 \cdot 2$ \\
\hline $22: 0$ & $0 \cdot 03$ & 0.03 & $0 \cdot 03$ & 0.03 & 0.03 \\
\hline $24: 1 n-9$ & 0.02 & 0.03 & 0.03 & 0.03 & 0.03 \\
\hline $24: 0$ & $0 \cdot 04$ & 0.05 & $0 \cdot 04$ & 0.05 & 0.04 \\
\hline SAFA & $72 \cdot 1$ & $71 \cdot 1$ & $69 \cdot 9$ & $69 \cdot 0$ & $64 \cdot 7$ \\
\hline MUFA & $13 \cdot 8$ & $14 \cdot 2$ & $15 \cdot 2$ & $15 \cdot 5$ & 17.9 \\
\hline PUFA & $14 \cdot 1$ & $14 \cdot 7$ & $15 \cdot 0$ & $15 \cdot 5$ & 17.4 \\
\hline $\mathrm{S} n-6$ & 11.9 & $12 \cdot 6$ & $13 \cdot 8$ & $13 \cdot 8$ & 16.8 \\
\hline MCSAFA & $57 \cdot 1$ & $57 \cdot 9$ & $55 \cdot 2$ & $54 \cdot 2$ & $48 \cdot 8^{*}$ \\
\hline LCSAFA & $15 \cdot 0$ & $13 \cdot 2$ & $14 \cdot 7$ & 14.9 & $15 \cdot 9$ \\
\hline $\mathrm{S} n-3>\mathrm{C}_{20}$ & $0 \cdot 4$ & 0.3 & $0 \cdot 3$ & $0 \cdot 3$ & 0.5 \\
\hline $\mathrm{S} n-6>\mathrm{C}_{20}$ & 0.7 & 0.7 & 0.8 & $0 \cdot 7$ & 0.9 \\
\hline LCPUFA & $1 \cdot 1$ & $1 \cdot 1$ & $1 \cdot 2$ & $1 \cdot 1$ & $1 \cdot 5^{*}$ \\
\hline
\end{tabular}

* Mean values for $\mathrm{OB}$ group were significantly different from those of all other groups $(P<0.05)$.

$\uparrow$ For details of treatments, see pp. 18-19.

MCSAFA, 6:0-14:0; SAFA, saturated fatty acids; LCSAFA, $\geqslant \mathrm{C}_{16: 0}$ MUFA, mono-unsaturated fatty acids; $\mathrm{S} n-6$, sum of $n-6$ fatty acids; PUFA, polyunsaturated fatty acids; $\mathrm{S} n-3>\mathrm{C}_{20}$, sum of $n-3$ fatty acids beyond chain length $\mathrm{C}_{20} ; \mathrm{S} n-6>\mathrm{C}_{20}$, sum of $n-6$ fatty acids beyond chain length $\mathrm{C}_{20} ;$ LCPUFA, sum of $n-3+n-6$ fatty acids beyond chain length $\mathrm{C}_{20}$.

second drug has been reported to show much reduced anti-glucocorticoid activity compared with Mifepristone (Neef et al. 1984). Neither compound affected adrenal gland weight throughout this study. It is concluded that anti-glucocorticoid action of the compounds is unlikely to play a role in suppression of litter weight gain.

Both compounds interfere with the suppression, through suckling, of pre-ovulatory follicular development after day 10 of lactation (van der Schoot et al. 1989). Interference with the suppressed follicular development, and thus oestrogen production, was judged an obvious candidate for explaining impaired litter growth (Zeilmaker, 1969). Indeed, injections of $\mathrm{OB}$ markedly interfered with litter growth, but the quantities used in the 
Table 6. Effect of treatment with Mifepristone or Onapristone on body and organ weights at the end of lactation (intact rats) $\dagger$

(Mean values with their standard errors)

\begin{tabular}{|c|c|c|c|c|c|c|c|c|c|c|}
\hline \multirow[b]{2}{*}{ Treatment } & \multicolumn{2}{|c|}{ Body-wt (g) } & \multicolumn{2}{|c|}{$\begin{array}{c}\text { Adrenal } \\
\text { gland (mg) }\end{array}$} & \multicolumn{2}{|c|}{ Ovaries (mg) } & \multicolumn{2}{|c|}{ Uterus (mg) } & \multicolumn{2}{|c|}{$\begin{array}{l}\text { Left inguinal } \\
\text { mammary } \\
\text { gland } \\
\text { at } 24 \mathrm{~h} \text { after } \\
\text { weaning (mg }\end{array}$} \\
\hline & Mean & $\mathrm{SE}$ & Mean & $\mathrm{SE}$ & Mean & SE & Mean & SE & Mean & $\mathrm{SE}$ \\
\hline Oil $(n 5)$ & 272 & 12 & 35 & 1 & 65 & 4 & 308 & 14 & 9028 & 614 \\
\hline Mifepristone ( $n 8)$ & 269 & 9 & 33 & 1 & 94 & 5 & 350 & 19 & 9437 & 770 \\
\hline \multirow[t]{2}{*}{ Onapristone $(n 7)$} & 268 & 7 & 34 & 1 & 63 & 3 & 305 & 20 & 9101 & 476 \\
\hline & \multicolumn{2}{|c|}{ NS } & \multicolumn{2}{|c|}{ NS } & \multicolumn{2}{|c|}{ * } & \multicolumn{2}{|c|}{ NS } & \multicolumn{2}{|c|}{ NS } \\
\hline
\end{tabular}

* Mean value for group treated with Mifepristone was significantly different from those of the other groups (ANOVA, one-way): $P<0.01$; NS, not significant.

$\dagger$ For details of treatments, see p. 18 .

Table 7. Effect of treating dams with $2 \mathrm{mg}$ Mifepristone/d or with oil on litter growth and on the estimated daily intake of food and water between days 10 and 17 of lactation $\dagger$

(Mean values with their standard errors for four rats)

\begin{tabular}{|c|c|c|c|c|c|c|c|c|c|c|}
\hline \multirow[b]{3}{*}{ Treatment } & \multicolumn{4}{|c|}{ Daily intake of dams } & \multirow{2}{*}{\multicolumn{2}{|c|}{$\begin{array}{c}\text { Food }+ \\
\text { water }(\mathrm{g})\end{array}$}} & \multirow{2}{*}{\multicolumn{2}{|c|}{$\begin{array}{l}\text { Daily litter } \\
\text { wt gain } \\
(\mathrm{g} / 24 \mathrm{~h})\end{array}$}} & \multirow{2}{*}{\multicolumn{2}{|c|}{ Quotient: }} \\
\hline & \multicolumn{2}{|c|}{ Food $(\mathrm{g})$} & \multicolumn{2}{|c|}{ Water $(\mathrm{ml})$} & & & & & & \\
\hline & Mean & SE & Mean & $\mathrm{SE}$ & Mean & SE & Mean & $\mathrm{SE}$ & Mean & $\mathrm{SE}$ \\
\hline Controls & 61 & 2 & 77 & 5 & 138 & 4 & 19 & 2 & $7 \cdot 2$ & $0 \cdot 1$ \\
\hline + Mifepristone & $53^{*}$ & $\overline{1}$ & $67^{*}$ & 5 & $120^{*}$ & 3 & $16^{*}$ & 1 & $7 \cdot 2$ & $0 \cdot 1$ \\
\hline
\end{tabular}

* Mean values significantly different from those of the control group (paired $t$-test; $P<0.01$ ).

For details of treatments, see pp. 18-19.

$\ddagger$ Quotient of the daily amounts of food and water taken by the mother and the daily weight gain of litter + mother.

present study lead to plasma oestradiol levels which are well above those encountered in the normal pre-ovulatory state (Tapper et al. 1974). The effect of both anti-progestins on litter growth was similar in lactating ovariectomized rats to that in lactating intact rats. It is, therefore, concluded that the ovaries do not play a role in the mechanism of litter growth impairment.

The large amount of Mifepristone injected into their mothers might give rise to effects in pups through the passage of the drug into the milk. No effort was made to examine concentrations of Mifepristone in milk. Examination of the effects of large amounts of Mifepristone, directly injected into suckling pups, seemed more appropriate. Newborn male and female rats showed no obvious adverse effects of such treatment with regard to body growth or external bodily features. After day 10 of lactation no effect on pup growth was observed. The period beyond day 10 represents the period of litter growth disturbance in mothers treated with the compound. Effects of Mifepristone on organ weights (testes and adrenal glands) on day 18 were considered proof of the bioavailability of subcutaneously injected Mifepristone in the newborn. The injected amounts of Mifepristone were far in 
Table 8. Effect of treatment with Mifepristone or oil on the mean weight changes of lactating dams and their litters during $6 \mathrm{~h}$ of separation on day 18 of lactation and the first and second hour after their reunion.*

(Mean values with their standard errors for four rats)

\begin{tabular}{|c|c|c|c|c|c|c|}
\hline & \multicolumn{4}{|c|}{ Wt changes ( $\mathrm{g}$ ) during: } & & \\
\hline & \multicolumn{2}{|c|}{$6 \mathrm{~h}$ of separation } & \multicolumn{2}{|c|}{$\begin{array}{l}\text { Ist hour } \\
\text { after reunion }\end{array}$} & \multicolumn{2}{|c|}{$\begin{array}{l}2 \text { nd hour } \\
\text { after reunion }\end{array}$} \\
\hline & Mean & $\mathrm{SE}$ & Mean & SE & Mean & $\mathrm{SE}$ \\
\hline \multicolumn{7}{|l|}{ Dams } \\
\hline Control & $9 \cdot 0$ & $2 \cdot 1$ & $-13 \cdot 8$ & $2 \cdot 6$ & $2 \cdot 5$ & $1 \cdot 7$ \\
\hline Mifepristone & $4 \cdot 3$ & $3 \cdot 8$ & $-13 \cdot 8$ & 1.9 & $-0 \cdot 3$ & $1 \cdot 2$ \\
\hline \multicolumn{7}{|l|}{ Litters } \\
\hline Control & $-3 \cdot 8$ & $0 \cdot 2$ & $12 \cdot 5$ & 1.6 & $0 \cdot 0$ & 0.1 \\
\hline Mifepristone & $-3 \cdot 0$ & 0.0 & $11 \cdot 5$ & $1 \cdot 6$ & $0 \cdot 5$ & 0.4 \\
\hline
\end{tabular}

* For details of treatments, see p. 18.

excess of those which could possibly have been ingested via the milk. Direct effects of Mifepristone on suckling pups were, thus, unlikely to be the source of disturbed litter growth.

Litter growth is, obviously, critically dependent on milk secretion. Evaluation of milk secretion is diffeult, but various indirect methods for estimating milk secretion are easily available. Litter removal in an advanced stage of lactation will result in engorgement of the mammary glands. The weight of accumulated milk can be estimated by measuring weight increases of the mammary glands. A different approach is the examination of litter weight increase after a temporary separation of litters from their mothers. On reunion, pups immediately grasp to the nipples. Milk becomes available rapidly and in large amounts both through direct expression ('tap reflex') and in response to oxytocin as revealed by specific behaviours of the sucking pups (Lincoln et al. 1973). Results of examination of both indices of milk secretion did not indicate that Mifepristone or Onapristone interfered with milk secretion. Moreover, the measurement of macronutrient and fatty acid composition of milk did not reveal effects of treatment with Mifepristone or Onapristone.

After the previous experiments had failed to elucidate the mechanism of litter growth disturbance, the final experiment aimed to examine litter growth in relation to intake of food and water by lactating rats. Until around day 18 of lactation litter weight increase is totally dependent on milk ingestion: direct observation of litters with their mothers never revealed attempts by pups to take solid food or water. Litter weight increase thus totally depends on: (a) amounts of food and water taken up by their mother and (b) efficiency by which ingested food is transformed into milk in the mammary glands. It appeared that dams treated with Mifepristone ingested significantly less food and water than controls. The mother's intake of food and water: litter weight increase ratio appeared identical in the two groups of rats. The total intake of food and water was highly correlated with litter growth. These observations lead to the possible explanation of disturbed litter growth, namely interference through Mifepristone with the usual intake of food and water required for normal litter growth.

Thanks are due to Dr R. DeRaedt (Roussel-Uclaf, Romainville, France) and Dr W. Elger (Schering, Berlin, Germany) for supplying Mifepristone and Onapristone respectively. 
Professor J. J. van der Werff ten Bosch is gratefully thanked for support throughout this study and constructive criticism during the preparation of this paper.

\section{REFERENCES}

Blanc, B. (1981). Biochemical aspects of human milk: comparison with bovine milk. World Review on Nutrition and Dietetics 36, 1-89.

Bruce, J. O. \& Ramirez, V. D. (1970). Site of action of the inhibitory effect of estrogen upon lactation. Neuroendocrinology 6, 177-182.

Clandinin, M. T., Chapell, J. E. \& Heim, T. (1982). Do low weight infants require nutrition with chain elongationdesaturation products of essential fatty acids? Progress in Lipid Research 20, 901-904.

Jansen, G., Muskiet, F. A. J., Schierbeek, H., Berger, R. \& van der Slik, W. (1986). Capillary gas chromatographic profiling of urinary, plasma and erythrocyte sugars and polyols as their trimethylsilyl derivatives, preceded by a simple and rapid prepurification method. Clinica Chimica Acta 157, 277-294.

Kirk, R. E. (1968). Experimental Design: Procedures for the Behavioral Sciences. Belmont: Brooks/Cole.

Knopp, R. H., Walden, C. E. \& Wahl, P. W. (1981). Oral contraceptive and postmenopausal estrogen effects on lipoprotein triglyceride and cholesterol in an adult female population: relationships to estrogen and progestin potency. Journal of Clinical Endocrinology and Metabolism 53, 1123-1132.

Koletzko, B., Schmidt, E., Bremer, H. J., Haug, M. \& Harzer, G. (1989). Effects of dietary long-chain polyunsaturated fatty acids on the essential fatty acid status of premature infants. European Journal of Pediatrics 148, 669-675.

Lincoln, D. W., Hill, A. \& Wakerley, J. B. (1973). The milk-ejection reflex in the rat: an intermittent function not abolished by surgical levels of anaesthesia. Journal of Endocrinology 57, 459-476.

Lowry, O. H., Rosebrough, N. J., Fatt, A. L. \& Randall, R. I. (1951). Protein measurement with the Folin phenol reagent. Journal of Biological Chemistry 193, 265-267.

Neef, G., Beier, S., Elger, W., Henderson, D. \& Wiechert, R. (1984). New steroids with antiprogestational and antiglucocorticoid activities. Steroids 44, 349-372.

Philibert, D. (1984). RU 38486: an original multifaceted antihormone in vivo. In Adrenal Steroid Antagonism, pp. 77-101 [M. K. Agarwal, editor]. Berlin: deGruyter \& Co.

Tapper, C. M., Greig, F. \& Brown-Grant, K. (1974). Effect of steroid hormones on gonadotrophin secretion in female rats after ovariectomy during the oestrous cycle. Journal of Endocrinology 62, 511-525.

Tucker, H. A. (1988). Lactation and its hormonal control. In The Physiology of Reproduction, pp. 2235-2263 [E. Knobil and J. Neill, editors]. New York: Raven Press.

van der Schoot, P. \& de Greef, W. J. (1983). Effect of adrenalectomy on the regulation of the secretion of gonadotrophins and prolactin in the lactating rat. Journal of Endocrinology 98, 227-232.

van der Schoot \& de Greef, W. J. (1986). Prolactin and delay of implantation in lactating adrenalectomized rats. Hormone Research 24, 46-54.

van der Schoot, P., Uilenbroek, J. Th. J. \& Slappendel, E. J. (1989). Failure of two progesterone-antagonists to affect luteal activity in lactating rats. Journal of Reproduction and Ferility 87, 593-601.

van der Schoot, P., Uilenbroek, J. Th. J. \& Slappendel, E. J. (1990). Effect of the progesterone-antagonist mifepristone on the hypothalamo-hypophysial-ovarian axis in rats. Journal of Endocrinology 124, 425-432.

van der Schoot, P., Uilenbroek, J. Th. J., Woutersen, P. \& Bakker, G. (1987). The progesterone antagonist Mifepristone, a tool for the study of the role of progesterone in regulating ovarian activity in rats. In Neuroendocrinology of Reproduction, pp. 161-168 [R. Rolland, E. V. van Hall, S. G. Hillier, K. P. McNatty and J. Schoemaker, editors]. Amsterdam: Elsevier.

van der Steege, G., Muskiet, F. A. I. \& Martini, 1. A. (1987). Simultaneous quantification of total medium- and long-chain fatty acids in human milk by capillary gas chromatography with split injection. Journal of Chromatography 415, 1-11.

Zeilmaker, G. H. (1969). Milk yield during prolonged lactation in mice: effects of ovariectomy. Journal of Reproduction and Fertility 19, 361-365. 